\title{
脳血管障害重複例の問題点
}

\author{
府川修, 相原 坦 道, 鶴見勇 治, 藤 森清
}

\section{Therapeutic Problem of Overlapped Cerebrovascular Diseases}

\author{
Osamu Fukawa, M.D., Hiromichi Aihara, M.D., Yuji Tsurumi, M.D., and
}

Kiyoshi Fujimori, M.D.

Department of Neurological Surgery, Irwaki Municipal Hospital, Iwaki, Japan

\begin{abstract}
Summary : Case histories of 44 patients with overlapped cerebrovascular diseases are presented in this paper. Combinations were mainly as follows: 11 cases of ruptured intracranial aneurysm-cervical internal carotid artery stenosis, eight cases of cerebral infarction-unruptured intracranial aneurysm, eight cases of intracerebral hematoma-unruptured intracranial aneurysm, and five cases of arteriovenous malformation-intracranial aneurysm. There were 20 surgical cases for main cerebrovascular diseases and 20 for coexisting cerbrovascular diseases. Surgical treatment for both main and coexisting cerbrovascular disease was performed in nine patients. Postoperative sequelae occurred in six cases. This was the result of coexisting ischemic cerebrovascular disease in five cases. Ischemic cerebral symptoms contralateral to the site of operation were especially observed in three patients. It should be noted that, in case of coexisting ischemic cerebrovascular disease, the postoperative sequela occurred, even when measures were taken to prevent lowering systoric blood pressure, to prevent hypovolemia, and when anticoagulants were administered during the operative procedure.
\end{abstract}

Key words :

- cerebral aneurysm

- cerebral infarction

- carotid stenosis

- operative treatment

- cerebrovascular disease

\section{はじめに}

脳血管障害重複例 (以下重複例と略す)の治療については, その重複した疾患の組み合わせによる病態像の複雑さから 個々に検討されるべきと考えるが，今回は自験例をもとに， 入院の原因となった疾患と重複した疾患の組み合わせごと に治療の内容をふりかえり，その問題点について検討を加 えた。

\section{症例}

昭和52年 1 月 1 日より 62 年 4 月 30 日までに当科で経験し た重複例は44例である (Table 1)。入院の原因となった脳血 管障害を主 CVD とするとその内容は, 出血性疾患32例, 虚血性疾患 11 例, その他 1 例 (外傷性クモ膜下出血で入院
し, 右一側脳血管モヤモヤ病と未破裂脳動脈瘤を合併した 症例)である。一方，主 CVDに重複した脳血管障害を副 CVD とすると, 44症例 46 疾患の内容は, 出血性疾患 26 例 (ただし無症候性)，虚血性疾患20例 (無症候性19例，症候 性 1 例)である。なお 2 例において 2 つの副 CVDを有し ていた，男女比は男 21 例，女23例であり，入院時平均年齢 は男子例では56.7歳，女子例では57.4歳であった.

主 CVD が出血性疾患であった32症例の内容 (Table 2) は, 破裂脳動脈瘤14例, 脳動静脈奇形 3 例, 脳内出血13例, 脳 室内出血 1 例, クモ膜下出血 1 例であった。この群では特 に，破裂脳動脈瘤症例において頸部内頸動脈狭窄を合併し ていた例が14例中11例，脳内出血例では未破裂脳動脈瘤を 合併していた例が13例中 8 例，と多くみられた。なお（） 内の数字は手術施行例であり, この群の主 CVD に対して 
は32例中18例に外科的療法が行われた.この群の副 CVD に対しては33例中12例に外科的療法が行われた。

一方, 主 CVD が虚血性疾患であった11例の内容 (Table 3) は, 脳梗塞 8 例, 頸部内頸動脈狭窄 1 例, 中大脳動脈狭 窄 2 例であった。この群では，脳梗塞に未破裂脳動脈瘤が 合併した例が 8 例中 7 例と多くみられたが, この群の主 CVD に対しては，11例中 2 例に外科的療法が行われた。

重複例の組み合わせのなかで頻度の高かったものは, 破 裂脳動脈瘤と頸部内頸動脈狭窄例11例, 脳梗塞と未破裂脳 動脈瘤例 8 例, 脳内出血と未破裂脳動脈瘤例 8 例, 脳動静 脈奇形と脳動脈瘤例 5 例などであった。これら重複例にお ける治療結果は以下の通りである。

Table $i$ Overlapped cerebrovascular diseases

\begin{tabular}{|c|c|c|c|}
\hline \multicolumn{2}{|c|}{ Main CVD } & \multicolumn{2}{|c|}{ Coexisting CVD } \\
\hline $\begin{array}{l}\text { hemorrhagic } \\
\text { disease }\end{array}$ & 32 cases & $\begin{array}{l}\text { hemorrhagic } \\
\text { (asymptomatic) }\end{array}$ & 26 cases \\
\hline ischemic disease & 11 cases & $\begin{array}{l}\text { ischemic disease } \\
\text { (asymtomatic) } \\
\text { (symtomatic) }\end{array}$ & $\begin{array}{r}19 \text { cases } \\
1 \text { cases }\end{array}$ \\
\hline other & 1 cases & & \\
\hline & 44 cases & & 46 cases \\
\hline
\end{tabular}

male; 21 average age 56.7 y.o. $(48-72$ y.o.)

female; 23 average age 57.4 y.o. (24-78 y.o.)

CVD; cerebrovascular disease

\section{破裂脳動脈瘤と頸部内頸動脈狭窄の合併例 (Table 4)}

主 CVD である破裂脳動脈瘤に対しては11例中10例に瘤 柄部クリッピング手術が行われた。このうち8 例は待期手 術例であり，2 例はクモ膜下出血後72時間以内の早期手術 例である. 副 CVD の頸部内頸動脈の狭窄率はすべて $50 \%$ 以上の症例であるが，これに対しては脳動脈瘤直達手術が 行われた10例のうちの 7 例に内膜摘除術 (CEA) が施行さ れた。このうち 5 例は脳動脈瘤手術後, 時期を遅らせて CEA が施行されており，2 例は同時期に施行された。こ れら11例中，結果の不良であった症例は，脳血管攣縮によ り外科的療法を行いえず死亡した 1 例と，両疾患に対して 同時期手術を行った 2 例の計 3 例である.

\section{脳内出血と未破裂脳動脈瘤の合併例 (Table 5)}

8 例全例が高血圧症の既往を有していたが，主 CVD と しての脳内出血に対しては 2 例にのみ血腫摘出術が施行さ れた。しかし重複した未破裂脳動脈瘤に対しては，血腫摘 出術を行った際に同一の視野で瘤柄部処置が行いえた 2 例 (いずれも血腫例の中大脳動脈瘤)にのみ同時期手術が行わ れ，他の 4 例は時期を遅らせて瘤柄部クリッピング手術が 行われた。この群に扔いては, 主 CVDの予後がそのまま 未破裂脳動脈瘤手術後の予後に反映しており, 全症例の退 院時の ADL は, excellent 3 例, good 1 例, fair 4 例で あった。

Table 2 A variety of coexisting cerebrovascular disease (CVD) in patient with hemorrhagic CVD as a main disease

\begin{tabular}{|c|c|c|c|}
\hline \multicolumn{2}{|c|}{ Main CVD } & \multicolumn{2}{|c|}{ Coexisting CVD } \\
\hline $\begin{array}{l}\text { ruptured intracranial } \\
\text { aneurysm }\end{array}$ & 14 (13) cases & $\begin{array}{l}\text { cerebral infarction } \\
\text { cervical IC stenosis }\end{array}$ & $\begin{array}{l}1(0) \text { cases } \\
11(7)\end{array}$ \\
\hline & & $\begin{array}{l}\text { MCA stenosis } \\
\text { AVM }\end{array}$ & $\begin{array}{l}1(0) \\
1(0)\end{array}$ \\
\hline AVM & $3(2)$ & $\begin{array}{l}\text { unruptured intra- } \\
\text { cranial AN } \\
\text { cervical IC stenosis }\end{array}$ & $\begin{array}{l}2(0) \\
1(0)\end{array}$ \\
\hline $\begin{array}{l}\text { intracerebral } \\
\text { hemorrhage }\end{array}$ & $13(3)$ & $\begin{array}{l}\text { unruptured intra- } \\
\text { cranial AN } \\
\text { cervical IC stenosis } \\
\text { cervical IC occlusion } \\
\text { blt. VA stenosis } \\
\text { MCA occlusion } \\
\text { cerebral infarction }\end{array}$ & $\begin{array}{l}8(5) \\
1(0) \\
1(0) \\
1(0) \\
1(0) \\
1(0)\end{array}$ \\
\hline $\begin{array}{l}\text { intraventricular } \\
\text { hemorrhage }\end{array}$ & $1(0)$ & $\begin{array}{l}\text { unruptured intra- } \\
\text { cranial AN }\end{array}$ & $1(0)$ \\
\hline $\begin{array}{l}\text { subarachnoid } \\
\text { hemorrhage }\end{array}$ & $1(0)$ & $\begin{array}{l}\text { intracranial AN } \\
\text { AVM }\end{array}$ & $\begin{array}{l}1(0) \\
1(0)\end{array}$ \\
\hline & $32(18)$ & & $33(12)$ \\
\hline
\end{tabular}

IC: internal carotid artery, MCA: middle cerebral artery, AVM: arteriovenous malformation, AN: aneurysm, VA: vertebral artery, ( ): surgical case. 
Table 3 A variety of coexisting cerebrovascular disease (CVD) in patient with ischemic CVD as a main disease

\begin{tabular}{lcll}
\hline \multicolumn{2}{c}{ Main CVD } & \multicolumn{3}{c}{ Coexisting CVD } \\
\hline cerebral infarction & $8(0)$ cases & unruptured intracranial AN & $8(7)$ cases \\
\hline cervical IC stenosis & $1(1)$ & unruptured intracranial AN & $1(0)$ \\
\hline MCA stenosis & $2(1)$ & $\begin{array}{l}\text { unruptured intracranial AN } \\
\text { AVM }\end{array}$ & $1(1)$ \\
& $11(2)$ & & $11(0)$ \\
\hline
\end{tabular}

( ) : surgical case.

Table 4 Eleven patients with ruptured intracranial aneurysm and cervical internal carotid artery stenosis

\begin{tabular}{|c|c|c|c|c|c|c|}
\hline \multirow[b]{2}{*}{ Case No. } & \multicolumn{3}{|c|}{ Main CVD } & \multicolumn{3}{|c|}{ Coexisting CVD } \\
\hline & Age/Sex & $\begin{array}{l}\text { Site of ruptured } \\
\text { intracranial AN }\end{array}$ & $\begin{array}{l}\text { Surgical } \\
\text { treatment }\end{array}$ & $\begin{array}{l}\text { Side of cervical } \\
\text { IC stenosis }\end{array}$ & $\begin{array}{l}\text { Surgical } \\
\text { treatment }\end{array}$ & $\mathrm{ADL}$ \\
\hline 1 & $59 / \mathrm{M}$ & A Com A, lt. IC-PC* & yes (delayed op.) & lt. & yes its & excellent \\
\hline 2 & $59 / \mathrm{F}$ & lt. IC-PC & no & lt. & no & dead \\
\hline 3 & $53 / \mathrm{M}$ & lt. IC-PC, rt. ACA* & yes (delayed op.) & rt. & yes is & excellent \\
\hline 4 & $46 / \mathrm{F}$ & rt. MCA & yes (delayed op.) & lt. & yes is & good \\
\hline 5 & $65 / \mathrm{F}$ & lt. IC-PC & yes (delayed op.) & lt. & no & excellent \\
\hline 6 & $63 / \mathrm{F}$ & $A \operatorname{com} A$ & yes (delayed op.) & rt. & yes $\hat{\imath}$ & excellent \\
\hline 7 & $58 / \mathrm{M}$ & lt. MCA & yes (early op.) & lt. & yes $\hat{z}$ & good \\
\hline 8 & $56 / \mathrm{M}$ & $A \operatorname{com} A$ & yes (delayed op.) & rt. & no & excellent \\
\hline 9 & $58 / \mathrm{M}$ & $A \operatorname{com} A$ & yes (delayed op.) & rt. & yes $\star$ & fair \\
\hline 10 & $62 / \mathrm{F}$ & lt. MCA & yes (delayed op.) & $\begin{array}{l}\text { rt. } \\
\text { lt. PCA occlusion }\end{array}$ & no & excellent \\
\hline 11 & $54 / \mathrm{M}$ & rt. IC & yes (early op.) & rt. & yes $\star$ & dead \\
\hline
\end{tabular}

A com A: anterior communicating artery, IC-PC: internal carotid-posterior communicating artery, MCA: middle cerebral artery, ACA: anterior cerebral artery, PCA: posterior cerebral artery, IC: internal carotid artery, ADL: activity of dailly living, ${ }^{*}$ :unruptured aneurysm, $i$ : different time operation, $\star$ : same time operation.

Table 5 Eight patients with intracerebral hematoma and unruptured cerebral aneurysm

\begin{tabular}{|c|c|c|c|c|c|c|}
\hline \multirow[b]{2}{*}{ Case No. } & \multicolumn{3}{|c|}{ Main CVD } & \multicolumn{3}{|c|}{ Coexisting CVD } \\
\hline & Age/Sex & $\begin{array}{c}\text { Site of } \\
\text { hematoma }\end{array}$ & $\begin{array}{l}\text { Surgical } \\
\text { treatment }\end{array}$ & $\begin{array}{l}\text { Site of } \\
\text { aneurysm }\end{array}$ & $\begin{array}{l}\text { Surgical } \\
\text { treatment }\end{array}$ & $\mathrm{ADL}$ \\
\hline 1 & $59 / \mathrm{M}$ & rt. thalamus & no & lt. IC & yes & fair \\
\hline 2 & $54 / \mathrm{M}$ & lt. putamen & yes & lt. MCA & yes $\star$ & fair \\
\hline 3 & $48 / \mathrm{M}$ & rt. thalamus & no & lt. MCA & yes & excellent \\
\hline 4 & $70 / \mathrm{F}$ & rt. occipital lobe & no & $\begin{array}{l}\text { rt. MCA } \\
\text { lt. ACA stenosis }\end{array}$ & no & good \\
\hline 5 & $72 / \mathrm{M}$ & rt. thalamus & no & rt. ACA & yes & excellent \\
\hline 6 & $60 / \mathrm{F}$ & lt. putamen & yes & lt. MCA & yes $\star$ & fair \\
\hline 7 & $53 / \mathrm{F}$ & lt. parietal lobe & no & It. MCA & yes & excellent \\
\hline 8 & $64 / \mathrm{F}$ & lt. thalamus & no & A com A & no & fair \\
\hline
\end{tabular}

A com A: anterior communicating artery, IC: internal carotid artery, MCA: middle cerebral artery, ACA: anterior cerebral artery, ADL: activity of dailly living, $\star$ : same time operation. 
Table 6 Eight patients with cerebral infarction and unruptured cerebral aneurysm

\begin{tabular}{ccccccl}
\hline & \multicolumn{3}{c}{ Main CVD } & \multicolumn{3}{c}{ Coexisting CVD } \\
\cline { 2 - 7 } Case No. & Age/Sex & Infarctic region & $\begin{array}{c}\text { Surgical } \\
\text { treatment }\end{array}$ & $\begin{array}{c}\text { Site of } \\
\text { aneurysm }\end{array}$ & $\begin{array}{c}\text { Surgical } \\
\text { treatment }\end{array}$ & ADL \\
\hline 1 & $59 / \mathrm{F}$ & mid-brain & no & lt. IC & no & good \\
2 & $68 / \mathrm{M}$ & lt. cerebrum & no & rt. ACA & yes & excellent \\
3 & $55 / \mathrm{M}$ & lt. cerebrum & no & A com A & yes & excellent \\
4 & $54 / \mathrm{F}$ & lt. cerebrum & no & lt. IC & yes & good \\
5 & $68 / \mathrm{F}$ & rt. cerebrum & no & A com A & yes & excellent \\
6 & $50 / \mathrm{M}$ & lt. cerebrum & no & lt. MCA & yes & good \\
7 & $54 / \mathrm{F}$ & lt. cerebrum & no & lt. IC, BA & yes & good \\
8 & $63 / \mathrm{M}$ & lt. cerebrum & no & lt. MCA & yes & excellent \\
\hline
\end{tabular}

A com A: anterior communicating artery, IC: internal carotid artery, MCA: middle cerebral artery, ACA: anterior cerebral artery, BA: basilar artery, ADL: activity of dailly living.

Table 7 Six patients with postoperative sequela

\begin{tabular}{|c|c|c|c|c|c|c|}
\hline \multirow[b]{2}{*}{ Case No. } & \multicolumn{3}{|c|}{ Main CVD } & \multicolumn{3}{|c|}{ Coexisting CVD } \\
\hline & Age/Sex & & $\begin{array}{l}\text { Surgical } \\
\text { treatment }\end{array}$ & & $\begin{array}{l}\text { Surgical } \\
\text { treatment }\end{array}$ & $\begin{array}{l}\text { postoperative } \\
\text { sequela }\end{array}$ \\
\hline 1 & $69 / \mathrm{F}$ & ruptured rt. IC AN & yes (delayed op.) & $\begin{array}{l}\text { It. cerebral } \\
\text { infarction }\end{array}$ & no & rt. hemiparesis \\
\hline 2 & $78 / \mathrm{F}$ & ruptured lt. MCA AN & yes (delayed op.) & $\begin{array}{l}\text { lt. MCA } \\
\text { stenosis }\end{array}$ & no & rt. hemiparesis \\
\hline 3 & $58 / \mathrm{M}$ & ruptured A com A AN & yes (delayed op.) & $\begin{array}{l}\text { rt. cervical } \\
\text { IC stenosis }\end{array}$ & yes $(\mathrm{CEA}) \star$ & lt. hemiparesis \\
\hline 4 & $54 / \mathrm{M}$ & ruptured rt. IC AN & yes (early op.) & $\begin{array}{l}\text { rt. cervical } \\
\text { IC stenosis }\end{array}$ & yes $(\mathrm{CEA}) \star$ & $\begin{array}{l}\text { malignant } \\
\text { hypertension } \\
\text { intraventricular } \\
\text { hemorrhage }\end{array}$ \\
\hline 5 & $68 / \mathrm{M}$ & lt. cerebral infarction & no & $\begin{array}{l}\text { unruptured } \\
\text { rt. ACA AN }\end{array}$ & yes & rt. hemiparesis \\
\hline 6 & $34 / \mathrm{F}$ & traumatic $\mathrm{SAH}$ & no & $\begin{array}{l}\text { unruptured } \\
\text { lt. IC AN } \\
\text { Moyamoya } \\
\text { disease }\end{array}$ & yes & lt. hemiparesis \\
\hline
\end{tabular}

A com A: anterior communicating artery, IC: internal carotid artery, MCA: middle cerebral artery, ACA: anterior cerebral artery, CEA: carotid endarterectomy, $\star$ : same time operation.

\section{脳梗塞と末破裂脳動脈瘤の合併例 (Table 6)}

脳梗塞に対しては薬物療法およびリハビリテーションを 行い, 8 例とも神経学的に改善所見を得た後，7例に対し て瘤柄部クリッピング手術を施行した。この7例の退院時 の ADL は, excellent 4 例, good 3 例であった.

\section{術後問題の生じた症例 (Table 7)}

44症例のうち主 CVD および副 CVD に対して外科的療 法を行った例は，それぞれ20例であり，このうち9例は両 CVD に外科的療法を施行したが，これら外科的療法例の うち, 術後続発症を認めた症例は 6 例である。この 6 例の うち主 CVD が破裂脳動脈瘤であった 4 例では脳動脈瘤の 手術後に，また他の 2 例では副 CVD としての未破裂脳動 脈瘤の手術後に続発症を認めた。すなわち続発症は 5 例
(Table $7 に お け る$ 症例 1，2，3，5，6）が重複した虚血性 病変に起因すると考えられる虚血症状を呈したものであり, 特に症例 $1,5,6$ においては非開頭側大脳の虚血性症状を きたした。これら 5 症例ではいずれも術中の低血圧は認め なかった。症例 1，5，6の続発症としての片麻痺は 2 日〜 14 日で消失したが, 症例 2 と 3 においては残存した。なお 症例 4 は, 以上の 5 症例と異なり, 術前から存在した高血 圧症が術後さらに高度となりコントロールできず，術後 12 日目に脳室内出血をきたして失った。代表例を呈示する. 〈症例 3〉58歳, 男性 (Fig. 1)

クモ膜下出血後 6 日目に入院したが，一人ぐらしのため 入院前 3 日間は絶食状態であった。 入院時の意識レベルは 1, 神経学的には項部強直のほかは異常を認めなかった。 入院時の CTにてクモ膜下出血所見を認め, さらに右大脳 

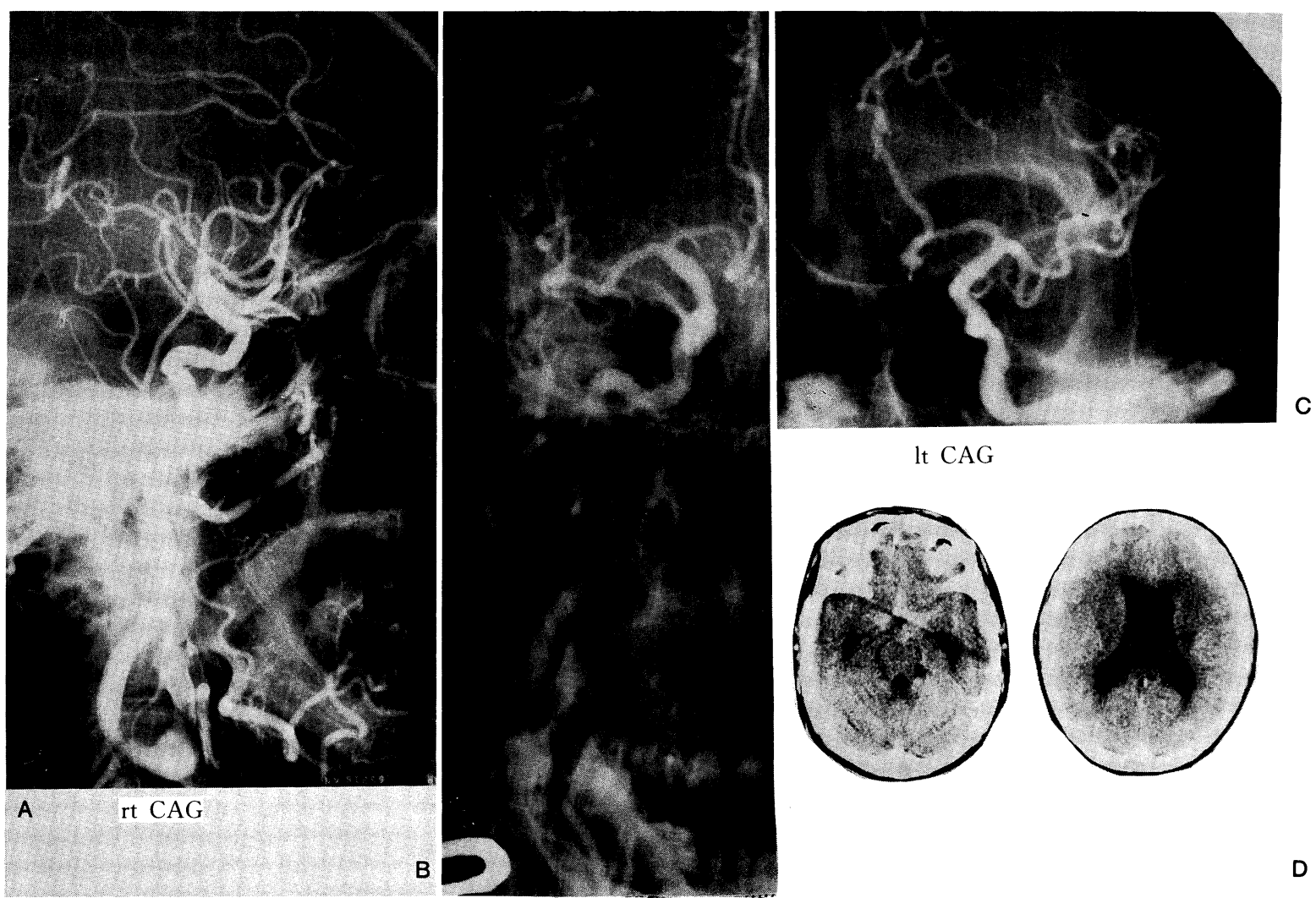

It $\mathrm{CAG}$

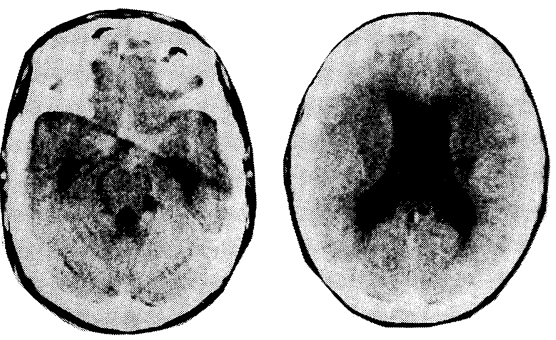

D

Fig. 1 Case 3 in table 758 y.o. male. A, B: Right carotid angiogram, 7 days after subarachnoid hemorrhage, showing marked stenosis of right cervical internal carotid artery and no vasospasm. C: Left carotid angiogram showing an anterior communicating artery aneurysm. D: CT on admission demonstrating subarachnoid hemorrhage and low density area in right paraventicular region.

基底核部と右傍側脳室部に小さな低吸収域を認めた，左頸 動脈撮影にて前交通動脈動脈瘤を認めたが, 脱水状態が著 明であり，血清クレアチニン值 $1.6 \mathrm{mg} / \mathrm{d} l, \mathrm{CRP} 4+$ を示 したため, 諸検査値のそろうのを待って開頭手術を行うこ ととした。ところが入院同夜, 左不全片麻痺が出現したた め, 発症 7 日目に右頸動脈撮影を行ったところ脳血管攣縮 像は認めなかったものの, 右頸部内頸動脈に高度の狭窄像 を認めた。発症 7 日目に瘤柄部クリッピング手術を行い, 抗凝固療法を行いつつ発症 8 日目に右 CEA を施行した. しかし左片麻瘦の改善は得られず, 手術 2 か月半後の退院 時の ADL は fairであった。

\section{〈症 例 6〉34歳，女性 (Fig. 2)}

CT 導入以前の症例であるが, 乗用車を運転中衝突事故 を起こして来院した，入院時の意識は清明であり, 神経学 的には特記すべき異常を認めなかったが, 頭痛と眼底出血 を認めたため左頸動脈撮影を行ったところ, 左内頸一後交 通動脈分岐部動脈瘤拐よび左前大脳動脈にそってその周囲 に存在するモヤモヤ様異常血管網を認めた。 な㧍髄液検査 で黄色調透明髄液を認め, 右頸動脈撮影ではいわゆる右一
側モヤモヤ病の所見であった。 入院 6 週間後, 上記の動脈 瘤に対して瘤柄部クリッピング手術を施行したところ術直 後より 2 日間にわたる左不全片麻疩の出現を認めた。退院 時の ADL は excellent であった。

\section{考案}

脳血管障害重複例の治療は，重複したそれぞれの疾患の 組み合わせと，それぞれの病態による複雑な要因を考慮し て検討されなければならないと考えるが, 従来重複例の発 生頻度でさえも正確にはとらえられていない. 自験例にお いてもすべての脳血管障害例に対して，全例にCT あるい は 4-vessel study などがなされているわけではなく，その 頻度は定かではない。しかし自験例についてみると, 脳動 脈瘤の関与した症例が 44 例中 36 例， $81.8 \%$ と多く，このう ち未破裂脳動脈瘤も21例， $47.7 \%$ と看過できない数であっ た。また頸部内頸動脈狭窄症または閉塞症も15例，34.1\% と多くみられた。

頻度の高かった重複例の組み合わせのうち, 破裂脳動脈 瘤と頸部内頸動脈狭窄症との合併例での治療上の問題点あ 


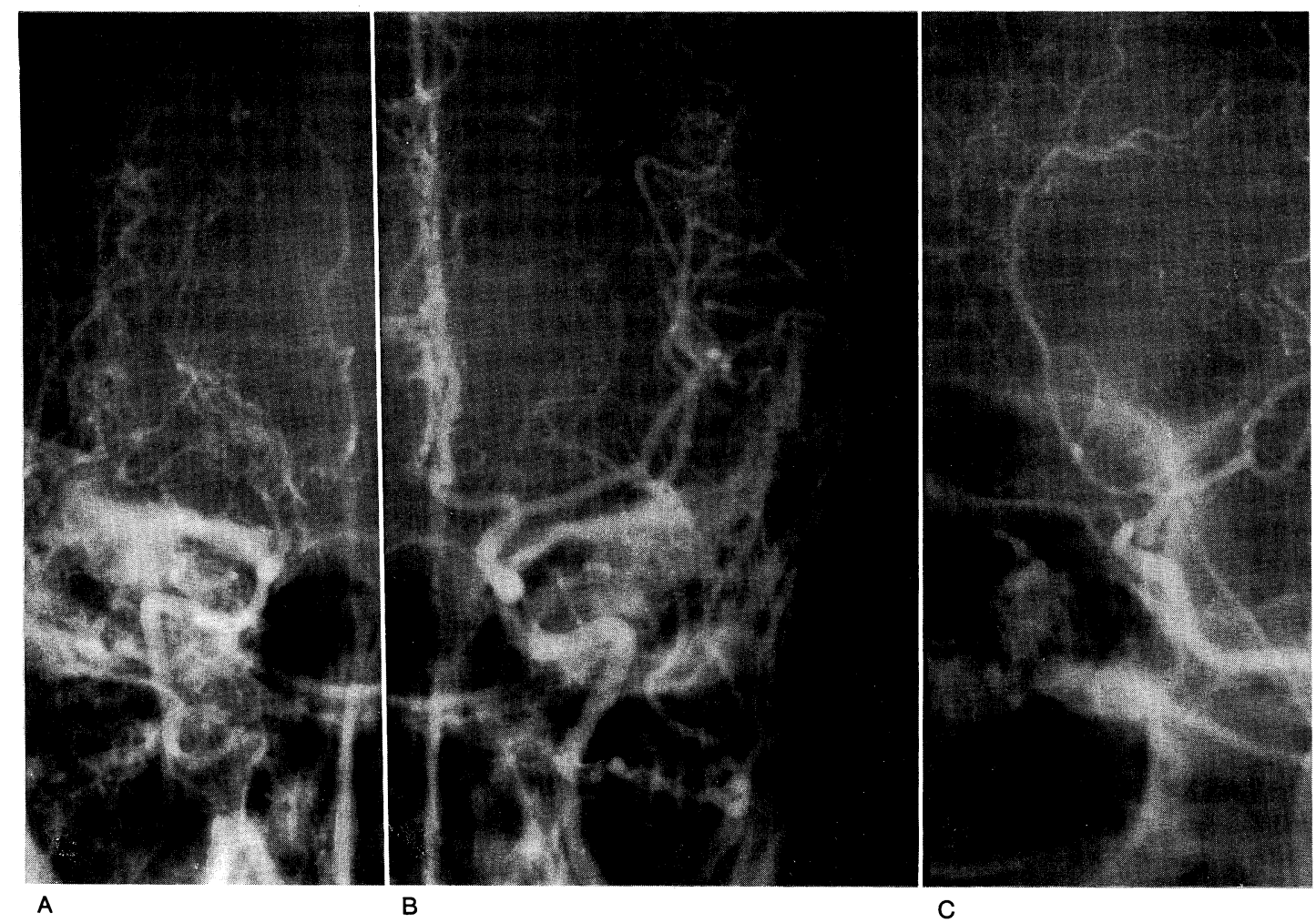

Fig. 2 Case 6 in table 734 y.o. female. A: Right carotid angiogram showing findings of unilateral cerebrovascular Moyamoya disease. B, C: Left carotid angiogram, oblique view showing an internal carotid-posterior communicating artery aneurysm.

るいは治療法の選択については，すでに報告 ${ }^{1) 2)}$ がある. われわれの症例ではこの組み合わせの場合，2つの疾患に 対してともに外科的療法を施行した例は 7 例であるが， 5 例では時期を異にして，2 例においては同時期手術を行っ ている.この 2 例のうちの 1 例は副 CVD としての頸部頸 動脈病変がembolic sourceとなっていたと考えられたため, 他の 1 例は脳動脈瘤と頸部頸動脈病変が同側に存在したこ とにより，脳血管攣縮が発生した場合のより高度な同側大 脳半球への low perfusion を危惧したため, 同時期手術を 行った。このような組み合わせ例においては，破裂脳動脈 瘤に対する処置を第一義とし，2つの病変が同側か否か, 同側であった場合の Willis 動脈輪の発達度, 頸動脈病変 が差し迫って支配血流領域に虚血性変化を惹起せしめうる か否かを考慮して，瘤柄部処置および CEA を同時期に行 うか否かを決めるべきと考える．なお主 CVD が頸部頸動 脈狭窄症であり，未破裂脳動脈瘤を伴った場合の治療方針 は，自験例では 1 例のみであるが，患者の状態が許す限り 原則的には両疾患とも外科的療法を行うべきであろうとわ れわれも考える ${ }^{3)}$.

脳梗塞と未破裂脳動脈瘤との合併例における治療方針, 成績については，北原ら ${ }^{4)}$ は20例中 7 例に，斉藤ら ${ }^{5)}$ は 9 例中の 5 例に未破裂脳動脈瘤に対する直達手術後の悪化例
を報告している．われわれもこの 2 つの疾患の組み合わせ において，8例中 7 例に瘤柄部クリッピング手術を行い， うち 1 例に術後非開頭側大脳の虚血症状の出現を認めた。 われわれの手術症例は全例脳梗塞の発症後最低 1 か月以上 を経過し，さらに神経症状の消失または改善傾向を示した 段階で，また術中の低血圧に留意しつつ手術を行った例で あるが，先行する虚血脳に起因する続発症にはさらに注意 を要するものと考える。な扮未破裂脳動脈瘤自体が embo-

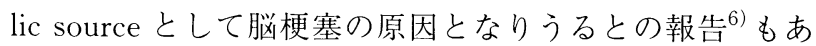
り，この点にも注意しておかなければならない.

脳内出血と未破裂脳動脈瘤との合併例における退院時の ADL は, 主 CVD である脳内出血の神経症状の改善度が そのまま副 CVD としての未破裂脳動脈瘤の直達手術後の ADL に反映していたことから，2つの疾患に対する同時 期手術は，脳内出血の手術に際して無理なく処置しうる動 脈瘤に対してのみ行うべきと考えた。

さて44症例中, 術後続発症を認めた 6 症例のうち 5 例は 重複した虚血脳または狭窄性血管病変に起因するものと考 えられたが，こうした症例については，術中，術後の血圧 の管理, hypovolemia の改善, 脳保護物質の投与, 抗凝固 療法など，より一層の注意を払うべきものと思われた。 


\section{まと め}

脳血管障害重複例44症例のうち主 CVD と副 CVD の組 み合わせ別にみると，頻度の高かったものは，破裂脳動脈 瘤-頸部内頸動脈狭窄症11例，脳梗塞-未破裂脳動脈瘤 8 例, 脳内出血-未破裂脳動脈瘤 8 例, 脳動静脈奇形-脳動脈瘤 5 例などであった。44例中，主 CVD あるいは副 CVD に対 してそれぞれ20例に外科的療法が施行された．特に 9 例に ついては両 CVD に手術がなされた。術後問題の生じた例 は6 例であった。このうち5 例は, 重複した虚血性病変が 関与しており, 特に 3 例では非開頭側大脳の虚血症状を認 めた。虚血性病変を合併した重複例の外科的療法を行う際, 術中, 術後の血圧の管理, hypovolemia の改善, 脳保護物 質の投与, 抗凝固療法などより一層の注意をはらうべきと 考えた。

\section{文献}

1）小川 彰, 桜井芳明, 嘉山孝正, 佐藤博雄：破裂脳動脈瘤に 合併した閉塞性血管病変の治療一急性期同時手術一. 第14回 日本脳卒中の外科研究会抄録集，1985,p 80

2) Stern J, Whelan M, Brisman R, Correll JW: Management of extracranial carotid stenosis and intracranial aneurysms. J Neurosurg 51: 147-150, 1979

3）梶原秀彦, 坚玉万典, 伊東山洋一, 松角康彦, 福村昭信：頭 蓋内動脈瘤を伴う内頸動脈狭窄症に対する外科的治療. そ の適応と考察. Neurol Med Chir (Tokyo) 25：815-820, 1984

4）北原茂美, 斉藤 勇, 瀬川 弘, 仁瓶博史, 岡田 崇: 脳梗 塞に合併した脳動脈瘤の手術. 第12回脳卒中の外科研究会講 演集，にゅーろん社，1983，pp 165-168

5）斉藤博文, 井上 明, 山際 修, 中井 昂, 八木直幸: 閉塞 性脳血管病変を伴う脳動脈瘤に対する治療方針の検討。第 10 回日本脳卒中学会抄録, 1983, p 141

6）西嶌美知春, 神山和世, 中田潤一, 岡 伸夫, 遠藤俊郎, 高 久 晃: 未破裂脳動脈瘤と脳梗塞. 第 10 回日本脳卒中学会総 会抄録, 1983, p 141 